\title{
NASHP Drug Pricing Proposal: A Step in the Right Direction
}

\author{
By: Amr Saleh (D)
}

At the heart of the COVID-19 pandemic is a longlasting question about access to healthcare in America. For years, exorbitant drug prices have caused severe problems for American patients. The ineffective system of determining drug costs, solely influenced by competition in the free market, leaves roughly $25 \%$ of Americans unable to afford prescription drugs ${ }^{1}$. Importantly, this emphasizes the urgent need for structural reform in this area. Interestingly, there has been a renewed political will to address this crisis. In May 2018, the Trump Administration released a blueprint to "put American patients first" and, in the report, "high list prices" was the first challenge identified by Health and Human Services ${ }^{2}$. Six states have already enacted laws that allow for Canadian drug importation but await for federal approval ${ }^{3}$. These initiatives at the state and federal level, while not amounting to formal legal action, set the stage for paradigm-shifting policies to be passed. The National Academy for State Health Policy (NASHP), a nonpartisan group of policy makers in state governments, represent a key actor for drug price reform ${ }^{4}$. Recently, they published a model law to match Canadian drug prices for the American market ${ }^{5}$. The model accounts for the 250 most expensive drugs in the state and proposes setting an upper limit defined by the lowest price found across Canada's four most populous provinces ${ }^{5}$. In doing so, this aims to decrease drug prices and improve drug accessibility. While not flawless, this model provides an effective starting point to regulate drug prices in America and addresses key critics.

The first primary argument against NASHP's proposal is limiting the research and development (R\&D) of pharmaceutical companies ${ }^{3}$. To illustrate, the argument suggests that lowering profit margins for these companies may hinder their capacity to develop new drugs and, by extension, the variety of drugs available to US consumers. However, this argument overlooks two key aspects. First, the pharmaceutical industry already holds significantly larger profit margins than other major markets. From 2000 to 2018, the profit margin of large pharmaceutical companies was $13.8 \%$ as opposed to $7.7 \%$ for large non-pharmaceutical companies $^{6}$. Clearly, the industry is able to afford profit cuts at the benefit of increased accessibility for patients. Second, pharmaceutical companies often get funding directly from the public through taxes. In a 2019 study by Nayak and colleagues, it was found that $19 \%$ of approved drugs by the US Food and Drug Administration (FDA) between 2008 and 2017 originated through publically supported research and development.

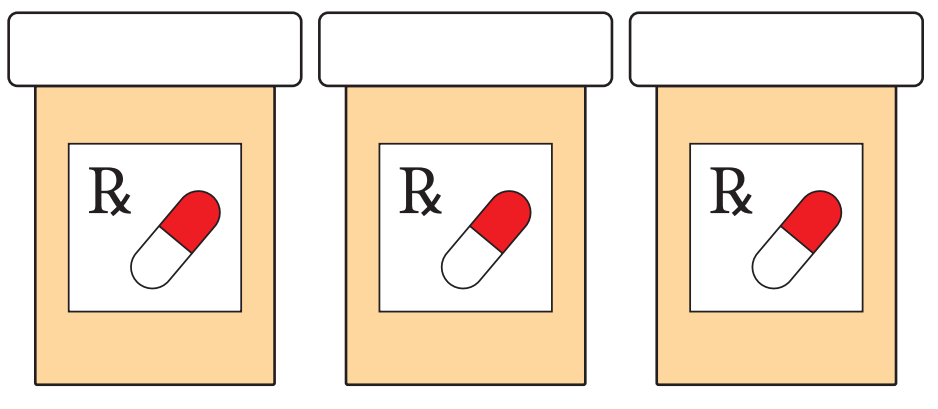

An image of prescription drug bottles

To strengthen the original critic, pharmaceutical companies risk a lot of money for drugs that may not get approved - shouldn't they get compensated? In other countries where governments negotiate prices, those same pharmaceutical companies are still able to conduct R\&D at significantly lower prices. The difference in these prices can be drastic, as outlined in NASHP's model law. For instance, Xeljanz, a drug used to treat mild arthritis in adults, is priced at $448 \%$ of what those in Quebec pay ${ }^{3}$. Evidently, if pharmaceutical companies are able to engage with lower prices in other global markets, then America should be no different.

A second argument against NASHP's proposal is with respect to company withdrawal from the American market $^{3}$. In other words, if profit margins become significantly lower, the argument claims that pharmaceutical companies may choose to withdraw from the American market altogether. The most prominent case of this is Vertex and their drug Orkambi. 
After being approved by the UK government for treating cystic fibrosis, the drug was denied to patients as a result of a deadlock between Vertex and the NHS over its price $^{8}$. However, there are structural differences between the American and UK market which makes market withdrawal very unlikely. First, the mere size of American market makes it unlikely companies, even with renewed lower profit margins, will not sell to American consumers. In fact, the United States represents nearly $46 \%$ of the global pharmaceutical market ${ }^{9}$. Clearly, not engaging with the American market poses drastic cuts to company revenue and profit. For this reason, Vertex represents a very rare case and instances where pharmaceutical companies choose to withdraw from a market are few and far between. In fact, Vertex, even with a smaller market in the UK, eventually resolved their pricing conflict with the NHS and made Orkambi available to consumers ${ }^{8}$. In the worst-case scenario in which a company intends to withdraw, NASHP's proposal outlines precautions and penalties for doing so. States may have existing consumer protection laws which could provide the legal framework for a lawsuit against companies that choose to withdraw. In addition, Section 9 c) outlines a $\$ 500,000$ penalty for any distributor or manufacturer that fails to comply with the renewed prices ${ }^{5}$.

Lastly, such a paradigm shifting proposal can be seen to oppose free market principles of the pharmaceutical market ${ }^{3}$. Contrary to countries like Canada where provincial governments negotiate drug prices, pharmaceutical companies in America are free to charge however they please and are only driven by competition in the free market. Setting a price cap is still in-line with free market principles. NASHP merely proposes setting an upper limit on what consumers can pay for a particular drug defined by the lowest price of Canada's four most populous provinces. Thus, companies are still able to compete in a free market. Moreover, the use of regulatory mechanisms regarding drug prices is found across the world. Currently, External Reference Pricing is used across Asia and is one of many strategies used to regulate drug prices ${ }^{10}$. The existence of these clear and well-defined regulation strategies outside America underscore the pressing need for reform.

If nothing else, NASHP's proposal, along with initiatives from individual states, give indication of the political will that is necessary for legislative reform. Additionally, COVID-19 has also exposed the broader socioeconomic factors intrinsically linked to health care. Thus, this proposal represents a step in the right direction in one aspect of a health care system that is complex, multifaceted, and, in some respects, deeply flawed.
Amr Saleh is a student at McMaster University. Please address correspondence to: saleha16@mcmaster.ca

\section{ACKNOWLEDGEMENTS}

I would like to thank Aria Ahmad for his invaluable assistance in guiding me through the research process while developing this article.

\section{COMPETING INTERESTS}

No competing interests declared.

Received: December 25, 2020

Accepted: February 22, 2021

Published online: March 22, 2021

\section{REFERENCES}

1. Kamal, R. What are the recent and forecasted trends in prescription drug spending? Peterson-KFF Health System Tracker (2019). Available at:https://www.healthsystemtracker. org/chart-collection/recent-forecasted-trends-prescription-drugspending/\#item-start. (Accessed: 19 November 2020)

2. The U.S. Department of Health \& Human Services. American Patients First. (2018).

3. Riley, T. Why Pay More? NASHP's New Model Law Uses International Drug Pricing to Lower Costs. The National Academy for State Health Policy (2020). Available at: https://www.nashp.org/ why-pay-more-nashps-new-model-law-uses-international-drugpricing-to-lower-costs/. (Accessed: 9th December 2020)

4. NASHP. About NASHP. The National Academy for State Health Policy. Available at: https://www.nashp.org/about/. (Accessed: 8th December 2020)

5. Staff, NASHP. An Act to Reduce Prescription Drug Costs Using International Pricing. The National Academy for State Health Policy (2020). Available at: https://www.nashp.org/an-act-to-reduceprescription-drug-costs-using-international-pricing/. (Accessed: 29th November 2020)

6. Ledley, F. D., Mccoy, S. S., Vaughan, G. \& Cleary, E. G. Profitability of Large Pharmaceutical Companies Compared With Other Large Public Companies. Jama 323, 834 (2020). doi: 10.1001/jama.2020.0442

7. Nayak, R. K., Avorn, J. \& Kesselheim, A. S. Public sector financial support for late stage discovery of new drugs in the United States: cohort study. Bmj 15766 (2019). doi:10.1136/bmj.I5766

8. Kmietowicz, Z. Cystic fibrosis drugs to be available on NHS in England within 30 days. Bmj 16206 (2019). doi:10.1136/bmj.I6206

9. Lindsley, C. W. New 2016 Data and Statistics for Global Pharmaceutical Products and Projections through 2017. ACS Chemical Neuroscience 8, 1635-1636 (2017). doi: 10.1021/ acschemneuro.7b00253

10. Verghese, N. R., Barrenetxea, J., Bhargava, Y., Agrawal, S. \& Finkelstein, E. A. Government pharmaceutical pricing strategies in the Asia-Pacific region: an overview. Journal of Market Access \& Health Policy 7, 1601060 (2019). doi: 10.1080/20016689.2019.1601060 